Derechos reservados de El Colegio de Sonora, ISSN 1870-3925

\title{
La construcción social de la escasez de agua. Una perspectiva teórica anclada en la construcción territorial
}

\author{
Esther Padilla Calderón*
}

Resumen: Desde la perspectiva del presente trabajo, el observable central para aprehender los procesos de construcción territorial y de escasez de agua es un tipo específico de relaciones sociales, las de confrontación. De acuerdo con Max Weber, cuando las acciones de un sujeto o un grupo se orientan por el propósito de imponer su voluntad contra la resistencia de otro u otros, se habla de relaciones de confrontación. Aquí, el eje de la noción de relación social es la confrontación, y desde esta propuesta teórico-metodológica es el observable fundamental en la comprensión del proceso de construcción social de un territorio y de la escasez de agua. Los ejes analíticos son: la relación entre construcción territorial y confrontación y entre confrontación y escasez.

Palabras clave: poder, confrontación, construcción social, territorio, territorialidad, escasez.

Abstract: From the perspective of this work, the main concept necessary to understand water scarcity and regional construction processes is a specific type of social relationship: confrontation. According to Max Weber, confronta-

\footnotetext{
* Profesora-investigadora del Centro de Estudios Históricos de Región y Frontera de El Colegio de Sonora.Teléfono: (662) 136 6358. Correo electrónico: epadilla@colson.edu.mx
} 
tion occurs when the actions of an individual or a group are guided by the purpose of imposing their will against the resistance of another or others. In this article, the core of the notion of social relationship is confrontation, and from this theoretical-methodological proposal arises the fundamental issue in understanding the process of the social construction of a territory and the scarcity of water. The analytical axes are: the relationship between territorial construction and confrontation, and between confrontation and scarcity.

Key words: power, confrontation, social construction, territory, territoriality, scarcity.

\section{Introducción}

Es conveniente aclarar que la posición teórica de este trabajo respecto a la escasez del agua es antropocéntrica, pues está centrada en la consideración de que dicha condición se construye con base en el desenvolvimiento de relaciones sociales de confrontación. Desde esta perspectiva, es importante entonces no confundir sequía con escasez; la primera está relacionada con condiciones naturales del medio, tiene un carácter climatológico, en tanto que la segunda hace referencia a procesos sociales. Es cuando la insuficiencia o inexistencia de agua, sentida por un sujeto o grupo, no se origina en un evento de sequía, sino en una distribución inequitativa del recurso agua. Por lo tanto, puede ocurrir que en un contexto determinado 'sequía' implique 'escasez', ya que un periodo de sequía puede ser un elemento interviniente en el desarrollo de una situación de escasez, pero ésta no presupone la presencia de una sequía, sino la desigualdad en el acceso al agua (Kloster 2008, 161-166). Por ello, la escasez no es una condición natural sino una construcción social, resultante del encajamiento de acciones de carácter social. ${ }^{1}$

\footnotetext{
${ }^{1}$ En las regiones áridas y semiáridas, las sequías son un fenómeno recurrente, de ahí que en estos lugares pueden influir en la construcción de situaciones de escasez, aunque no necesariamente.
} 
Ahora bien, desde el enfoque teórico-metodológico que ha orientado este trabajo, la construcción social de una situación de escasez de agua sólo puede ser aprehendida considerando el modo cómo se ha construido socialmente el territorio donde se ha producido y se vive la escasez; por este motivo, el punto de partida es una conceptualización en torno a los procesos de construccióndeconstrucción social de un territorio. ${ }^{2}$

A partir de una propuesta teórica concreta, se observan los territorios como lugares donde se producen condiciones materiales y sociales de existencia; como ámbitos que se construyen mediante confrontaciones en las que se involucra el poder (Marín 1995, 67-131). No obstante, existen otras concepciones y perspectivas teóricas de territorio. Para algunos autores, el concepto alude al espacio material donde ocurren cosas, donde las personas viven y se reproducen; para ellos es un ámbito dado, no lo conceptualizan como un espacio que se construye y destruye, como uno procesual, cambiante, producto de relaciones sociales de poder, esto es, de acciones de confrontación.

En este trabajo, las confrontaciones son los “observables" de las llamadas relaciones de poder; ${ }^{3}$ pues así en abstracto, ¿cómo podrían ser observadas en la realidad? Pero las confrontaciones, las peleas entre grupos o individuos sí pueden ser captadas, registradas y estudiadas. Aquí es donde se encuentra la fuerza de la teoría que fundamenta este trabajo: tiene el rigor de sugerir observables, ya que no es producto de un proceso especulativo sino de una reflexión anclada teórica y empíricamente.

Estudios realizados desde diferentes disciplinas de las ciencias sociales hablan de territorios, en términos de espacios materiales habitados por grupos sociales, y de las relaciones antagónicas y

\footnotetext{
2 Agradezco a Juan Carlos Marín, María Luisa Torregrosa, Karina Kloster y José Luis Moreno por acompañar, en diferentes momentos, la realización de este trabajo.

${ }^{3}$ Un "observable" es "desde el inicio, el producto de la unión entre un contenido dado por el objeto, y una forma exigida por el sujeto a título de instrumento necesario de toda verificación. [...] Podemos pues, considerar el 'hecho' —ya sea que se trate de una propiedad, de una acción o de un evento cualquiera - como un observable, pero a partir del momento en que es 'interpretado', es decir, revestido de una significación relativa a un contexto más amplio [...].” (Piaget y García 1984, 24).
} 
conflictos ocurridos entre blancos e indios, negros y blancos, entre otros. Tratan de la defensa de los territorios, vistos como espacios materiales donde habitan personas que los defienden de 'otros'. Estudian las pugnas alrededor de un territorio, describen los enfrentamientos, mas no los conceptualizan (Lieven 1999; Murray 2000). Otros autores pudieran estar aludiendo a procesos de construcción de territorios sociales, sin embargo de ninguna manera lo explicitan. Wolch y Dear (1988), por ejemplo, lo describen como unidad geográfica en la cual se desenvuelve la vida social y que a su vez conforma la vida social que se desarrolla en él. Esta dialéctica territorial socioespacial crea las posibilidades para que las relaciones se mantengan.

En otros estudios, territorio es sinónimo de región, considerada la existencia de ésta en términos de su relativa homogeneidad sociológica. Las personas habitan los territorios, y un territorio comprende un área de tierra más la gente que ahí habita (Grosby 1997). Para Ives Lacoste $(1977,50)$, geógrafo francés, el problema epistemológico con la región geográfica, "considerada como la representación espacial, si no única sí al menos fundamental, entidad supuestamente resultante de la síntesis armoniosa y de las herencias históricas $[\ldots]$ ”, es que en no pocas ocasiones ha hecho las veces de "camisa de fuerza" impidiendo "la toma en consideración de otras representaciones espaciales y el examen de sus relaciones". Lyman y Scott (1967) conceptualizan "territorialidad" como el intento de controlar el espacio físico, y lo conciben como una actividad humana fundamental.

Estas concepciones, desarrolladas y empleadas en distintos momentos históricos por estudiosos de disciplinas sociales, no aluden claramente a procesos de construcción de territorios sociales. Algunos reconocen que éstos cambian, pero no hablan acerca de su construcción/deconstrucción, ni de procesos de confrontación que hacen posible la constitución de territorios nuevos y la deconstrucción de los preexistentes.

La propuesta teórica de territorio retomada aquí es sociológica, y difiere de la concepción tradicional de la geografía, la historia e incluso la sociología, es decir, de la que vincula el concepto con el espacio material. Desde esta perspectiva, un territorio es siempre 
social, es un ámbito donde se producen condiciones sociales y materiales de existencia, asimismo, toda territorialidad es social, entendida ésta en el sentido amplio de un espacio de poder y disputa (Marín 1995, 67-131).

\section{Lacoste, Foucault y Marín: poder y territorio}

Ives Lacoste, geógrafo, y Michel Foucault, "arqueólogo del saber”, al estar en la base de la concepción de territorio construida por Juan Carlos Marín, comparten no pocos elementos con el sociólogo argentino. Para Lacoste, el territorio es el espacio y el terreno estratégico "por excelencia", es el lugar "donde se enfrentan las fuerzas encontradas y se desarrollan las luchas actuales" (1977, 83).

Para Foucault, "territorio, es sin duda una noción geográfica", pero "es en primer lugar una noción jurídico-política: lo que es controlado por un cierto tipo de poder" $(1979,116)$. Al reflexionar sobre la geografía, Foucault lista nociones geográficas como territorio, dominio, suelo, región, horizonte, y señala que "no son, ciertamente, estrictamente geográficas", aunque sean "nociones básicas de cualquier enunciado geográfico". Por lo tanto, ciertas nociones espaciales son tanto geográficas como políticas, ya que hacen referencia a formas de dominación, de control.

Marín coincide con Foucault, quien señala que la noción de territorio es geográfica, pero que en última instancia se refiere a "lo que es controlado por un cierto tipo de poder" (1979, 116); entonces, para él no es una estrictamente geográfica y, desde su perspectiva, es un concepto "estratégico", útil para el estudio de las relaciones de poder y sus efectos.

La escuela de geografía encabezada por Lacoste surgió como otras, de la crítica a ciertas corrientes dentro de la geografía, y tomando distancia de las que eran dominantes en este campo del conocimiento. Para Lacoste, la geografía "es un saber estratégico, un poder" y tiene relación con la articulación de conceptos referentes al espacio. Su utilidad práctica se vincula con la dirección de las guerras, la organización de los Estados y la práctica del poder $(1977,9)$. 
Esta concepción de lo geográfico presenta importantes similitudes con la propuesta sociológica de Marín, al instalar permanentemente las relaciones de poder en los procesos sociales vinculados con la constitución y defensa de territorios; para Lacoste, "la geografía tiene por objeto las prácticas sociales [...] en relación al espacio terrestre", es "el terreno estratégico por excelencia, el lugar, el territorio donde se enfrentan las fuerzas encontradas y donde se desarrollan las luchas" (Ibid., 81 y 83).

Ya que un territorio es un ámbito donde se producen condiciones sociales y materiales de existencia, constituir dichas condiciones implica edificar territorios (Marín 1995, 142 y 189). ${ }^{4}$ Y lo social tiene lugar cuando se produce la territorialidad (espacio de poder y disputa) (Marín 1995, 82). Lo social se produce cuando una parte de los individuos expropia a otra sus condiciones de existencia por medio de la fuerza material, la usa para crear dichas condiciones, que desarrolla y hace posible mediante el uso de la fuerza (Ibid., 81). ${ }^{5}$

En este contexto, al hablar de lo social se hace referencia a una relación social: "[...] es el encajamiento, la correspondencia entre acciones sociales, la relación entre acciones sociales” (Ibid., 79). Los territorios son ámbitos construidos por las relaciones entre los hombres, que se producen a través de acciones sociales, que no se crean en forma aislada, sólo existen y se reproducen por su capacidad de encajamiento y correspondencia con otras acciones, de ahí que produzcan relaciones sociales. Y como las acciones entre hombres pueden estar mediadas por las cosas u otros cuerpos, entonces las relaciones so-

\footnotetext{
${ }^{4}$ Los territorios deben su existencia a los hombres, "el mundo en que hemos nacido no existiría sin la actividad humana [...] que se ocupa de él, como en el caso de la tierra cultivada; que lo estableció mediante la organización, como en el caso del cuerpo político”. La acción "es prerrogativa exclusiva del hombre; [...] y sólo ésta depende por entero de la constante presencia de los demás" (Arendt 1974, 40).

${ }^{5}$ El poder está siempre presente, desde la fundación de lo social, desde la ruptura de la llamada 'doble existencia': "En las formas primarias de organización social [...] todavía no aparecen las mediaciones sociales entre el cuerpo y las condiciones de existencia, porque también la horda es casi el cuerpo mismo. [...] La ruptura se produce cuando entre la existencia objetiva y la existencia subjetiva se interpone la sociedad, cuando la 'doble existencia' se escinde $[\ldots]$ ya no hay una relación directa entre el cuerpo y las condiciones naturales, lo ‘social` media entre ambos" (Ibid., 77-79).
} 
ciales son sistemas de acciones entre individuos mediadas por cosas o cuerpos (Ibid., 97-103).

Ya que una acción social "permite captar el proceso de producción y reproducción de lo real”, se hace necesario distinguir los tipos de acciones (Ibid., 180-181). Entonces, un territorio se construye mediante relaciones sociales de poder, a través de acciones de confrontación. Dicho elemento conceptual se refiere a enfrentamientos o disputas entre sujetos antagónicos, que al querer o defender algo producen una resistencia en otro u otros sujetos. Las confrontaciones se expresan de modos diversos, a través de acciones específicas realizadas por individuos concretos.

Con una definición central de Max Weber, es posible precisar que una relación social es una de lucha "cuando la acción se orienta por el propósito de imponer la propia voluntad contra la resistencia de la otra u otras partes" (2004, 31). Así mismo, puede decirse que existe un "otro" que cuando pretende imponer su voluntad se encuentra con la determinación de su adversario de resistir, y la resistencia puede verse como el proceso de defensa de un territorio (Kloster 2008, 98).

El poder puede ejercerse a través de la acumulación de fuerza material (física) o del poder político que exprese una fuerza social, la cual es territorialidad y expresión de una alianza de clases (Marín 1995, 154). ${ }^{6}$ El poder está presente en el momento de la expropiación, que es posible porque hay una acumulación previa de éste, porque el expropiador ejerce más poder o tiene más fuerza (física). ${ }^{7}$

Una confrontación se resuelve cuando uno de los bandos obtiene el control sobre el territorio y los recursos. Marín señala que "un grupo lucha contra otro para quitarle un territorio, no para adueñarse de los cuerpos que viven allí -este 'consumo productivo' se puede dar como consecuencia" (Ibid., 82). Luego cita a H. Laborit, quien indica que "si el territorio estuviese vacío no sería de-

\footnotetext{
${ }^{6}$ Las territorialidades no coinciden con las clases sociales, sino que son cortadas trasversalmente por ellas (Ibid., 160).

7 "El enfrentamiento no es fuente de poder, no hace referencia al proceso de formación de poder, sino al de su realización”, al de su expresión (Ibid., 163).
} 
fendido. Únicamente es defendido porque contiene objetos y seres gratificantes, pues si dichos objetos y seres fueran peligrosos para la supervivencia, se huiría del territorio y no se lo defendería $[\ldots]$ " (Ibid., 82).

Hablar de una relación de confrontación para apropiarse un territorio, y obtener el control sobre los recursos que contiene (es decir, para construir una nueva territorialidad) es hablar de una relación de poder, que según se resuelva favorecerá a unos sobre otros. Los que ejerzan más poder podrán tener el control sobre los recursos y determinar cuándo y cómo aprovecharlos. Construir un territorio implica enfrentarse con otros, ya que "en el momento mismo en que se constituye una territorialidad, se establece la defensa de esa territorialidad, se establece la relación de confrontación $[\ldots]$ ante "los otros'” (Ibid., 142). Los territorios son sociales, y constituyen en relación con otros, el ámbito de la confrontación, es decir, de las relaciones de poder (Ibid., 143).

En la construcción de un territorio ocurren en forma simultánea la apropiación y la expropiación. "El proceso de apropiación, es el proceso mediante el cual se construye la territorialidad que reproduce en forma ampliada las personificaciones histórico-sociales" (Ibid., 197); el de expropiación constituye una acumulación, pues "a diferencia de la apropiación, crea la acumulación que permite -en secuencia y posteriormente- producir una apropiación ampliada”. Hablar de apropiación y expropiación es aludir a la construcción de lo social: "Y la especie humana es eso, es una especie que construye incesantemente territorios, territorios con los que establece un intercambio [...]" (Ibid., 196-197).

Marín dice que, en el ámbito total de la realidad hay uno original y diferenciado que "podemos caracterizar como el ámbito del poder" (Ibid., 153). "Enunciado de otra forma, podríamos decir que la clave del poder es la construcción de territorialidades sociales". La sociedad se reproduce a sí misma a través de relaciones de poder, mediante confrontaciones, debido a las cuales se construyen y destruyen relaciones sociales, o sea, territorialidades. Marín sugiere también otro concepto que identifica como "la capacidad de producir y reproducir poder"; no todas las territorialidades construidas logran reproducirse, a menudo se "evanecen, porque no logran el poder 
material suficiente" (Ibid., 157). La capacidad de "producir y reproducir poder" tiene que ver con la capacidad de reproducir una territorialidad. Si el poder se ejerce, y produce relaciones sociales producto del encajamiento de acciones, entonces la imposibilidad o dificultad de una territorialidad para reproducirse estaría relacionada con la imposibilidad o dificultad para que las acciones sociales que la constituyen continúen encajando, ocurriendo de manera referenciada.

\section{Investigaciones alrededor de la relación agua y poder}

La relación entre agua y poder o los procesos relativos al control social del agua han sido estudiados desde diferentes perspectivas teóricas, y en su definición -para el planteamiento y desarrollo de estudios sociales- ha sido importante la dilucidación del territorio, que se define como constituyente del objeto de estudio. Karl Wittfogel (1966), por ejemplo, en un trabajo clásico sobre la relación entre el llamado "poder totalitario" y el recurso agua, estudia áreas enteras dominadas por un mismo tipo de organización política como la China antigua, Egipto, India, Turquía y algunas sociedades mesopotámicas, a las que conceptualiza como sociedades hidráulicas, cuya base reproductiva estaba en el control total que el Estado "despótico” ejercía sobre el agua. Dichos Estados totalitarios mantenían dominada a la sociedad a través del control exclusivo sobre el acceso al agua, lo cual era posible mediante un gran aparato burocrático que controlaba y centralizaba todas las decisiones respecto al uso socioproductivo del recurso.

Arthur Maass y Raymond Anderson (1976), por su parte, compararon sistemas de riego tradicionales del levante español y otros del oeste estadounidense, estudiaron cómo los usuarios los operaban. Su perspectiva teórico metodológica es diferente a la de Wittfogel, pues los sistemas analizados por Maass y Anderson formaban parte de sociedades muy distintas de las estudiadas por Wittfogel, y además sus dimensiones físicas eran mucho menores, y estaban organizados y administrados por los propios usuarios. Las preguntas que orientaron su investigación eran distintas; aludían a otras 
escalas de los muy diversos órdenes sociales analizados por estos cientistas sociales. Buscaban los objetivos sociales detrás de las formas culturales de administración de pequeños sistemas de riego, y encontraron que el control del uso y la distribución del agua en esos lugares tenían un carácter significativamente autogestivo y democrático.

Concluyeron que las formas de manejar los sistemas de riego dependen de múltiples factores, tanto medioambientales como socioculturales, y que el manejo de los conflictos-considerados por ellos como situaciones permanentes- es más eficiente para los usuarios del sistema de riego en la medida en que sea mayor la cohesión de los sujetos o grupos que antagonizan.

Donald Worster, en Rivers of Empire (1985) presenta un modelo sobre el oeste estadounidense, lo caracteriza como "imperio hidráulico”, dominado por una elite que usa la tecnología hidráulica más avanzada. El control de la naturaleza implica el de los grupos sociales; y a los procesos constituyentes de este tipo de dominación los llama "ecología del poder". En realidad Worster se ha inspirado en el modelo marxista de Wittfogel, a quien dedica buena parte de sus reflexiones. Señala que el dominio del agua a gran escala requiere de un Estado centralista fuerte y una alianza sólida entre éste y sus aliados y beneficiarios principales.

Sobre México, los trabajos de Luis Aboites (1998) y Aboites y Valeria Estrada (2004) son centrales para la comprensión de la relación agua y poder. A través del estudio de procesos de centralización y federalización del manejo del agua, se advierten cambios ocurridos en el país sobre la gestión de este recurso, al tiempo que se construyen y consolidan regímenes políticos distintos. En los modos como va instalándose la relación entre el Estado y la sociedad en función de los usos del agua, se nota una condición cada vez más dominante, centralista del Estado mexicano, y de la federación sobre los estados y municipios.

Desde la antropología, Jacinta Palerm y Tomás Martínez (2000) sumando la perspectiva de Maas -sobre conflictos- al concepto de organización propuesto por R. Hunt, abordan los procesos conflictivos considerándolos como situaciones permanentes, cuya importancia radica en la capacidad organizativa de los usuarios de un 
sistema para resolverlo de manera favorable para todos los involucrados. Estos autores identifican y analizan las relaciones entre usuarios del agua e instituciones que regulan la distribución del recurso, analizando la capacidad autogestiva de los usuarios y la intervención estatal; sus estudios corresponden al México contemporáneo.

Martín Sánchez (2005) elaboró un trabajo de carácter histórico sobre el Bajío mexicano; su perspectiva de análisis incorpora el concepto braudeliano de larga duración, y discurre sobre el control del agua para riego incorporando de manera importante los cambios tecnológicos en materia hidráulica. Al considerar los planteamientos de Aboites, Sánchez reconoce que "como parte del ejercicio del poder, el estudio del control y administración de las aguas nos ayuda a entender el proceso de formación del Estado moderno en México." Sánchez aborda los "conflictos" a partir de la relación entre usuarios e instancias gubernamentales intervinientes, empleando para ello conceptos antropológicos de William Kelly, quien alude de manera importante al manejo de la autoridad.

Las investigaciones de Rocío Castañeda (1995 y 2005) sobre Puebla y Chihuahua relevan los aspectos hidráulicos en relación con la propiedad o posesión de la tierra, así como los conflictos en torno al uso de los recursos agua y tierra. En su trabajo sobre Puebla, Castañeda presenta a Jack Porter y Lewis Coser, quienes informan teóricamente su investigación sobre conflictos alrededor de los recursos tierra y agua. Desde su perspectiva, los problemas pueden producir efectos positivos en las relaciones sociales, si bien Coser aclara que no siempre propician el mantenimiento de la unidad de grupo. Para la autora, los conflictos son vías a través de las cuales pueden llegar a establecerse nuevos acuerdos (2005, 17-21).

Antonio Escobar elaboró un trabajo histórico sobre el control del agua en una región de San Luis Potosí, desde un enfoque que considera a este recurso natural como tal y también como uno político. Enfatiza -de acuerdo con planteamientos de Aboites- el rol desempeñado por el Estado mexicano en la conformación de instrumentos legales de control, que le permiten centralizar decisiones respecto a los usos del agua. Asimismo, recupera un enfoque antropológico para mostrar cómo los vínculos sociopolíticos permiten a ciertos actores controlar el agua a escala local (2005). 
La historiadora Elizabeth Fitting investigó sobre hechos de control del agua en una zona de Puebla, los examinó como "un proceso de lucha constante por el agua, una lucha que se desarrolla a la sombra de tensiones entre el Estado y la comunidad". Se apoyó en el concepto gramsciano de "hegemonía”, para señalar cómo los actores sociales subordinados adoptan formas y lenguajes de los grupos dominantes para ser tomados en cuenta (2007).

José Luis Moreno (2006) estudió una zona particularmente importante para el desarrollo económico de Sonora, su trabajo versa sobre el control del agua en la Costa de Hermosillo, enfatiza la sobreexplotación del agua subterránea en esa región sonorense. Describe procesos que producen una situación desigual en torno al acceso al agua entre agricultores de varios grupos sociales, y llama la atención sobre el manejo discursivo que las instancias que controlan esa área productiva hacen de la "escasez de agua", para manipular la opinión pública y expropiar el recurso a los productores que no son parte de ese grupo dominante. Emplea conceptos como la "apropiación de la naturaleza", y sigue planteamientos relacionados con la sustentabilidad ambiental y la geohidrología.

Por último, interesa resaltar el trabajo de Thomas Sheridan sobre el control del agua en la parte alta de la subcuenca del río San Miguel, en Sonora (1988). Su investigación ha sido guiada por el concepto "corporatividad", elabora una etnografía para entender el control de los recursos naturales escasos en la región de Cucurpe, en un contexto de aridez en una sociedad agraria, caracterizada por la inequidad y los conflictos políticos. La corporatividad considera a la comunidad como unidad básica de control de los recursos naturales, y plantea que la adaptación de los grupos campesinos a las condiciones del medio ambiente determina en forma más directa la economía campesina, que la intervención de actores externos de grupos de elite. Conjunta los enfoques de la economía política y la ecología cultural, y al suyo lo ha llamado "de ecología política", al considerar que la ecología de cualquier comunidad humana es política, al estar determinada y restringida por otros grupos humanos.

La relación agua y poder se ha abordado en función de preguntas de investigación específicas, y desde perspectivas teóricas que han 
permitido responder los interrogantes. Así se ha avanzado a escalas nacional e internacional en la comprensión de la relación agua y sociedad, considerando en general que el Estado y los regímenes que ha reproducido -con sus respectivas alianzas-, se han construido y fortalecido en función del control y la mediación de la gestión y los usos del recurso en diferentes escalas del orden social. Los conflictos en torno a la gestión y usos sociales del agua se han estudiado desde concepciones teóricas diversas y casi siempre en su interrelación con el uso social de otros recursos, en particular la tierra.

Aquí la propuesta teórico-metodológica se orienta a considerar las relaciones sociales de confrontación como constitutivas de las de poder, con base en las cuales se construyen y destruyen territorios sociales. Estos procesos guardan relación con la construcción social de situaciones de escasez de agua; bajo este enfoque aparece el trabajo de Karen J. Bakker (2000), que establece de manera explícita la construcción de la escasez de agua. Los contextos histórico y social a los que alude, así como el objeto tienen sus especificidades. Aquí se considera importante referirse de forma explícita a la escasez de agua como una construcción de carácter social. Bakker señala que la sequía de 1995 en Yorkshire, al norte del Reino Unido, es el evento climático más extremo ocurrido en este lugar desde que se privatizó el servicio de agua potable, en 1989. La sequía motivó un cambio sustantivo, porque los industriales y el gobierno aprovecharon el evento para instalar el tema de la escasez e imponer una nueva regulación alrededor del agua potable.

Bakker plantea de forma crítica que a la sequía ocurrida se le impute directamente la generación de una situación de escasez, y establece que ésta no sólo se relaciona con la sequía, sino que es producto de tres factores: las condiciones meteorológicas, el pronóstico de la demanda de agua potable y el juego regulatorio. "Exploro simultáneamente los elementos natural, social y discursivo de la escasez de agua y los sitúo dentro de un análisis de privatización como re-regulación, más que desregulación” $(2000,26)$.

Por lo que aquí se advierte, se han producido numerosos trabajos significativos y ya clásicos, por los interrogantes que en su momento se plantearon y las respuestas que construyeron, que en 
gran medida continúan vigentes. Esta revisión de investigaciones ha permitido considerar que también los procesos de control del agua pueden estudiarse desde una propuesta que instala como observables las confrontaciones en los procesos de constitución de territorios sociales.

\section{Construcción de la escasez de agua en un ejido sonorense}

La propuesta teórica presentada permite reflexionar sobre un ámbito rural existente en todo México -sin obviar sus especificidades-, el ámbito ejidal, y observarlo como un espacio que se construye y donde se producen condiciones de existencia; como un territorio que no preexiste a quienes lo conforman, y que no existe sin las confrontaciones que lo generan, es decir, sin que se hayan producido procesos de apropiación y expropiación territorial.

Por lo tanto, es posible pensar un ejido como un ámbito que es defendido y como un espacio social por el cual se lucha porque contiene recursos -agua, tierra, fuerza de trabajo-, que hacen posible que individuos y grupos produzcan y reproduzcan sus condiciones de vida. Con frecuencia en los ejidos se han enfrentado situaciones de escasez de agua, y en los modos - diferenciales- como han ocurrido y se han "resuelto" está involucrada la capacidad de "producir y reproducir poder". 8

El ejido San Miguel de Horcasitas y su anexo Los Ángeles fueron creados en 1935 en el valle de Horcasitas, Sonora, en un territorio con una historia específica alrededor del uso, apropiación y expropiación de los recursos naturales. ${ }^{9}$ Este ejido quedó constituido por pobladores de la Villa de San Miguel de Horcasitas y el pueblo de

\footnotetext{
${ }^{8}$ En este contexto "resolver" no quiere decir que llegado un determinado momento ya no haya escasez, que se termine, sino que ante ella se instalan resoluciones que con frecuencia son diferentes para los distintos grupos sociales, de modo que se determina que haya agua para unos y no para otros.

${ }^{9}$ Archivo del Registro Agrario Nacional, delegación Sonora (ARAN-H), caja 1, expediente 1-4-118, 8 de abril de 1935, fojas $0514-0516$.
} 
Los Ángeles, cuyas historias socioproductivas son diferentes aun si han compartido algunas experiencias en este campo ${ }^{10}$ (véase figura 1). Las diferencias entre estos pueblos produjeron formas organizativas distintas durante el proceso de reforma agraria, y también al construir soluciones a la situación de escasez de agua que enfrentaron después. ${ }^{11}$

Aunque en términos generales, el gobierno mexicano concedía una dotación de agua al tiempo que otorgaba tierras para la constitución de un ejido, en el caso del de Horcasitas y su anexo esto no ocurrió de forma simultánea. ${ }^{12}$ En un primer momento, el acceso al agua para riego fue más difícil para los campesinos-ejidatarios de Los Ángeles, porque sus tierras estaban consideradas como de temporal irrigable y no tenían derechos de agua al ocurrir el reparto agrario, mientras que las de San Miguel, cedidas al ejido, sí eran de riego. ${ }^{13}$

${ }^{10}$ Desde 1843 el uso productivo del agua en el territorio sonorense estuvo normado por el "Reglamento para la distribución y conservación de las aguas en los pueblos de Sonora". Según éste, las tomas que pertenecieran a particulares pero que estuvieran dentro de los pueblos dejarían a beneficio de la comunidad el agua sobrante. Este régimen de distribución del agua produjo "tierras con buen derecho de agua" y "tierras con regular o mal derecho", y continuó vigente hasta la década de 1930 (Bojórquez 2006, 168-177; Almada y Medina 2001, 180).

${ }^{11}$ En San Miguel de Horcasitas, los pobladores practicaban predominantemente la agricultura, un hacendado poseía 56 por ciento de la superficie cultivable y otros eran pequeños propietarios, jornaleros y pequeños ganaderos. Las tierras eran irrigadas por medio del canal Bacajúsari, que derivaba el agua del río San Miguel. Al formarse el ejido, las principales propiedades privadas fueron expropiadas. Archivo del Registro Agrario Nacional (ARAN), expediente 23/4651, legajo 1, Dotación de tierras, 26 de diciembre de 1922, foja 89; ARAN-H, caja 1, expediente 1-1-118, mayo 20 de 1931, foja 001; ARAN-H, caja 1, expediente 1-1-118, documento sin fecha, fojas 0034 - 0042.

En Los Ángeles, los pobladores eran obreros de la fábrica textil que existía en esta localidad desde el siglo xIx, otros eran agricultores y ganaderos en pequeña escala, algunos más prestaban diferentes servicios y no pocos eran jornaleros. Los propietarios de la fábrica habían permitido a los pobladores, que surtían la leña para las calderas, instalarse en una zona cercana a la manufactura, y en ésta sembraban fracciones y almacenaban instrumentos de trabajo. Irrigaban sus cultivos aprovechando la lluvia, haciendo tajos sobre el río, y otros "indebidos" sobre el canal Las Haciendas con que se regaban las tierras de las haciendas localizadas aguas abajo del pueblo. ARAN-H, expediente 1-2-118, caja 2, Censo General y Agropecuario de San Miguel de Horcasitas, 21 de noviembre de 1933, fojas 1433-1542; entrevista a José Carranza, realizada por Esther Padilla, el 7 de noviembre de 2006, en Hermosillo, Sonora; ARAN-H, expediente 1-4-118, caja 1, Comisario de policía de Los Ángeles al presidente de la Comisión Local Agraria, 12 de octubre de 1933, foja 0538.

12 ARAN-H, caja 2, expediente 1-5-118, 8 de abril de 1935, foja 1034.

${ }^{13}$ ARAN, expediente 33/5898, Dotación de aguas (local), 15 de febrero de 1936, foja 2. 


\section{Figura 1}

Ubicación de San Miguel de Horcasitas y Los Ángeles, Sonora

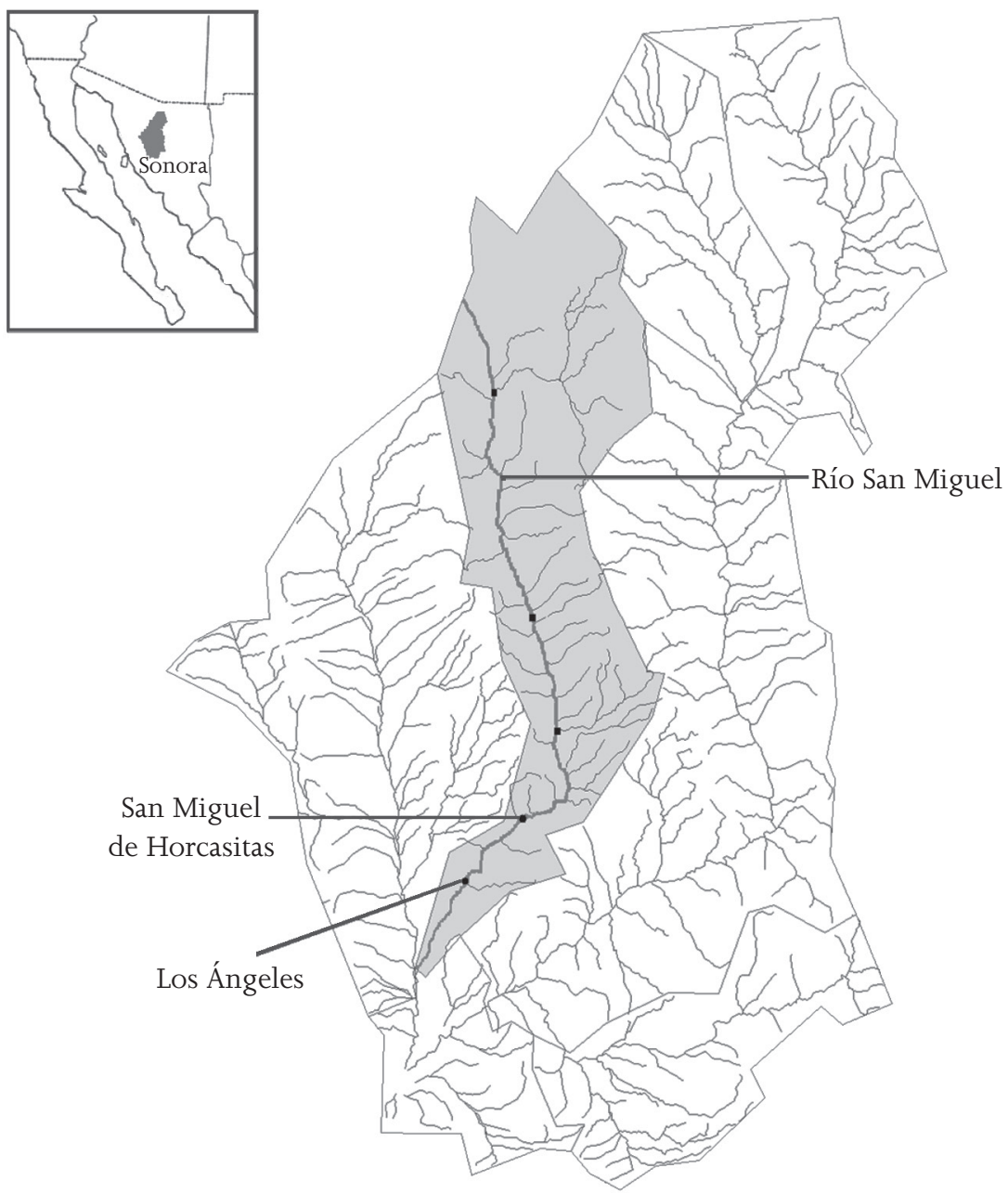

Fuente: elaboración propia.

Los campesinos de Los Ángeles impugnaron, pues no tenían acceso al agua que fluía frente a sus tierras, porque ésta se destinaba a irrigar predios de haciendas situadas aguas abajo del pueblo, y obtuvieron la concesión de un viejo canal conocido desde entonces 
como de Los Licenciados, con éste irrigarían las tierras de la margen izquierda del pueblo. ${ }^{14}$ Para regar la superficie de la margen derecha derivaban agua del canal de Las Haciendas, pero los hacendados manifestaron su desacuerdo y la delegación agraria los apoyó. ${ }^{15}$ Los campesinos de Los Ángeles construyeron entonces, con apoyo del comisariado ejidal, el canal de Los Locos, para regar dicha superficie, tomando el agua en un punto sobre el río localizado aguas arriba de la toma del canal de Las Haciendas. ${ }^{16} \mathrm{Al}$ construir la obra fortalecieron su territorialidad al apropiar y expropiar una parte de la territorialidad de otros, de los antiguos apropiadores del agua. Esta determinación para obtener agua tenía su origen en la organización que los campesinos habían conformado en los primeros años de la década de 1930, para obtener -mediante su adscripción ejidal-, la regularización de las tierras que usufructuaban en calidad de posesionarios. A través de las acciones coordinadas por su organización -el Sindicato de Campesinos de Los Ángeles- obtuvieron la legalización de sus posesiones y el agua.

En San Miguel de Horcasitas se produjeron inicialmente algunas confrontaciones por el agua entre pequeños propietarios y ejidatarios, debidas al orden de los riegos, vinculado con la disponibilidad de agua en el canal Bacajúsari. En estos desacuerdos, el ayuntamiento apoyaba a los pequeños propietarios y el ejido recibía el respaldo de las instancias agrarias. ${ }^{17}$ Estas confrontaciones se manifestaron a niveles individuales y también entre las corporaciones -el ejido y la pequeña propiedad, el ayuntamiento y la delegación agraria-, que a su vez eran instancias constituyentes de los gobiernos estatal y federal.

No obstante estas primeras confrontaciones, los ejidatarios de Los Ángeles y San Miguel tenían agua para producir, pero hacia

\footnotetext{
14 ARAN, expediente 33/5898, Dotación de aguas (local), 15 de febrero de 1936, foja 2; ARAN, expediente 33/5898, Dotación de aguas (local), 24 de octubre de 1935, foja 25; ARAN, expediente 33/5898, Dotación de aguas (local), 23 de marzo de 1942, foja 33.

15 ARAN-H, caja 1, expediente 1-4-118, 13 de diciembre de 1937, foja 0710.

16 ARAN, expediente 33/5898, Dotación de aguas (local), 17 de julio de 1939, foja 18.

17 ARAN-H, caja 1, expediente 1-4-118, 16 de octubre de 1938, foja 0853; ARAN-H, caja 1, expediente 1-4-118, 18 de octubre de 1938, foja 0852; ARAN, expediente 33/5898, Dotación de aguas (local), 17 de julio y 18 de agosto de 1939, fojas 18 - 23.
} 
1944 comenzó un periodo de escasez, que tuvo efectos importantes en el desarrollo del ejido. Los grupos sociales que habitan el territorio lo atribuyen a una sequía. ${ }^{18}$ Sin embargo, como ya se señaló, es importante no confundir "sequía" con "escasez". Dicho periodo alcanzó su "resolución social” en 1955, según testimonios orales y documentos. En este mismo lapso se presentó una sequía prolongada; ${ }^{19}$ cabe señalar que el valle de Horcasitas es climáticamente semiárido y las sequías son un fenómeno recurrente.

Los registros climatológicos indican que la sequía fue de 1944 a 1957 , se conoce localmente como "la sequía grande" 20 y fue un elemento interviniente en la construcción social de la situación de escasez de agua en el ejido San Miguel de Horcasitas y en su anexo Los Ángeles, porque la disminución en la disponibilidad de agua del río potenció e incrementó en ambos casos el control social de ciertos grupos sobre este recurso. Sin embargo, en el caso del núcleo de Los Ángeles resulta claro que situaciones significativas de escasez fueron instaladas aun antes; en 1943, el gobierno estatal impuso una normatividad para el canal de Los Locos y los campesinos de la margen derecha de Los Ángeles vieron la reducción del volumen de agua que fluía por su canal; ${ }^{21}$ y los que regaban tierras de la margen izquierda también vieron que se redujo la disponibilidad de agua del canal de Los Licenciados, porque hasta entonces habían recibido un volumen significativo, a través del canal de Los Locos. ${ }^{22}$

En 1947, en el contexto de "la sequía grande", la escasez de agua para riego en Los Ángeles se instaló con mayor intensidad cuando el gobierno del estado, a través de la Dirección de Obras, hizo cambiar el sitio de la bocatoma del canal de Las Haciendas y

\footnotetext{
${ }^{18}$ Un periodo de sequía es cuando la precipitación pluvial disminuye sensiblemente en un territorio, es decir, por debajo de la media anual.

${ }^{19}$ Comisión Nacional del Agua (Conagua). Datos medidos de precipitaciones en la estación climatológica El Orégano, localizada a $25 \mathrm{~km}$ de Los Ángeles. Es la estación más cercana al ejido de Horcasitas, con registros relativos al periodo de interés.

20 Entrevista con José Carranza, ex ejidatario de Los Ángeles, nacido en 1929 (Hermosillo, Sonora, 1 de noviembre de 2007).

21 Archivo Histórico del Agua (AHA). Fondo Aprovechamientos superficiales, caja 564, expediente 6209, legajo 1, 9 de marzo de 1943, foja 2.

22 ARAN-H, caja 271-71,118/1/S-3, 16 de enero de 1950, foja 322.
} 
construir una compuerta, con tal nivel que captaba prácticamente todo el volumen de agua del río que en forma natural debía correr aguas abajo. ${ }^{23}$

La escasez enfrentada en 1947 por los campesinos de la margen izquierda de Los Ángeles guarda relación con la sequía que comenzó en 1944, pero no sólo con ésta, porque las modificaciones hechas por el gobierno a la infraestructura para posibilitar y mejorar la captación de agua del río impedían que los campesinos de Los Ángeles captaran agua para cultivar las tierras de la margen izquierda. Además, en 1949, después de dichos cambios en el canal de Las Haciendas, se reglamentó el acceso al agua del río captada y conducida por éste, y así el territorio de Los Ángeles fue excluido. ${ }^{24}$

De 1947 a 1954, los campesinos de Los Ángeles se confrontaron de modos diversos con quienes les expropiaron el agua y, por fin, en 1954, lograron el reconocimiento institucional de sus derechos al agua del río San Miguel, aunque fue "provisional", y se legalizó hasta $1990 .{ }^{25}$ Las reglamentaciones relacionadas con el canal de Las Haciendas fueron instaladas para controlar jurídicamente el agua, y desempeñaron un papel trascendente en las posibilidades objetivas de control del recurso: las "reglas del juego" jurídicas, sobre la distribución y uso del agua, colaboraban en la reproducción del dominio de unos usuarios sobre otros.

En San Miguel de Horcasitas, los conflictos alrededor del agua -entre propietarios privados y ejidatarios hasta antes de la segunda mitad de los años cuarenta-, produjeron situaciones pasajeras y en este sentido poco trascendentes de escasez, porque no impidieron la reproducción de la actividad agrícola en el núcleo ejidal. Sobre todo se trataba de alteraciones breves en el orden de los riegos o de la exclusión momentánea de algunos productores respecto del acceso al agua. Estos conflictos se cruzaron con antagonismos entre instancias corporativas y niveles de gobierno.

\footnotetext{
${ }^{23}$ Archivo General del Estado de Sonora, (AGES), caja 210, tomo 1690, 412'6’46/1, documento del año 1952, s/f.

${ }^{24}$ ARAN-H, caja 1, expediente 1-1-118, marzo 28 de 1952, fojas 0058 - 0063.

25 ARAN-H, caja 1, expediente 1-1-118, documento del año 1973, fojas 0023 - 0030; Archivo de Concentración de la Gerencia Regional del Noroeste de la conAGUA, expediente único, Boletín Oficial del Gobierno del Estado de Sonora, 6 de febrero de 1990.
} 
La sequía que inició en 1944 está vinculada con la condición de escasez de agua de mayores efectos, que se produjo en San Miguel a fines de esta década. Ahí la sequía fue un elemento interviniente en mayor medida de la escasez que en el caso de Los Ángeles, porque la fuente superficial -el río San Miguel- se vio alterada por la sequía en el tramo en que alimentaba al canal Bacajúsari, a tal grado que debió ser reemplazada por otra y en ocasiones complementada con ella: el agua subterránea. ${ }^{26}$

Los territorios de San Miguel y Los Ángeles se han servido de la misma fuente -el río San Miguel-, pero el comportamiento hidrológico de ésta no es igual a lo largo de su cauce y no lo fue en el periodo estudiado. En ambas localidades, la fuente tuvo alteraciones durante la sequía que empezó en 1944; respecto al territorio de Los Ángeles, el río se secó en el punto de la bocatoma original del canal de Las Haciendas; ${ }^{27}$ en cuanto al de San Miguel, el río disminuyó de forma sensible su caudal hasta quedar seco durante el estiaje, cuando se sembraba trigo, el cultivo comercial más importante. ${ }^{28}$

Cuando el río se secó, la bocatoma fue relocalizada, porque un kilómetro aguas arriba seguía brotando agua sobre el cauce del río, fenómeno que no se presentó en San Miguel de Horcasitas. La estructura geológica del acuífero del río San Miguel a la altura de Los Ángeles es distinta a la de la villa de San Miguel, y los efectos de la sequía fueron diferentes (Padilla 2008, 196-264).

Desde mediados de los años cuarenta se produjo un proceso socialmente significativo de emigración de ejidatarios de San Miguel por causas diversas: la sequía, la ineficiencia del sistema crediticio ejidal y mejores oportunidades de vida en otras regiones del no-

26 ARAN, expediente 33/5898, Dotación de aguas (local), 5 de agosto de 1946, fojas 82 y 83.

${ }^{27}$ Entrevista con José Carranza, ex ejidatario de Los Ángeles, nacido en 1929 (Hermosillo, Sonora, 1 de noviembre de 2007).

${ }^{28}$ Éste se producía de octubre a mayo (tiempo de secas), cuando la temperatura del medio ambiente lo permitía, aprovechando el agua que continuaba fluyendo en el cauce del intermitente río San Miguel. Entrevista con Salvador Contreras Valenzuela, hijo de un viejo ejidatario de San Miguel de Horcasitas (San Miguel de Horcasitas, marzo 8 de 2008). Entrevista con Salvador Solís, ejidatario de San Miguel de Horcasitas, nacido en 1919 (San Miguel de Horcaditas, octubre 9 de 2005 y marzo 8 de 2008). 
roeste mexicano. La sequía y luego la escasez son factores que se cruzaron con procesos sociales que estaban ocurriendo a otra escala, y que intervinieron en la emigración de ejidatarios de este núcleo, relacionada con el deterioro de las condiciones de vida y la búsqueda de una mejor alternativa; que ocurre durante la sequía y en el contexto de construcción de la escasez de agua en el ejido. Las condiciones de los ejidatarios que se fueron y de los que se quedaron no eran homogéneas, y esto tiene relación con el poder que expresaban sus identidades individuales (Ibid., 244-250).

Alrededor de 1948 comenzaron a operar dos pozos "de luz" (poco profundos) en San Miguel de Horcasitas, y entonces el agua extraída de éstos y la poca que escurría del río hacia El Bacajúsari la utilizaban quienes permanecieron en el ejido (también por pequeños propietarios), pero no por todos. ${ }^{29}$ Quienes ejercían mayor poder en el interior de este núcleo ejidal aprovecharon los pozos perforados, usufructuaron las tierras que les habían "dejado encargadas" los que se fueron, y capitalizaron conjuntamente los recursos existentes (Ibid., 236-240).

En el caso del pueblo de Los Ángeles también se produjo un proceso migratorio importante, pero éste ocurrió en los primeros años de la década de 1940, y se relaciona con el cierre de la fábrica textil; entonces los obreros emigraron. La situación de escasez en Los Ángeles tuvo una existencia temporal mucho menos duradera que la que se ha padecido en San Miguel de Horcasitas (Ibid., 182-184).

Los habitantes del ejido perciben socialmente la escasez de agua como la insuficiencia o inexistencia del recurso para la producción agrícola. La forma cómo se enfrentó y resolvió dicha escasez para la agricultura en el ejido San Miguel de Horcasitas en el lapso considerado fue diferente en cada una de las localidades que lo conforman. El modo como se resolvió supuso que unos tuvieran agua y pudieran seguir reproduciéndose como ejidatarios y que otros enfrentaran más dificultades para reproducir su identidad $y$, en algunos casos, abandonaran el territorio.

29 ARAN-H, caja 1, expediente 1-1-118, Hermosillo, Sonora, 15 de noviembre de 1965, fojas 0135 y 0138; entrevista con Salvador Solís Carrillo, San Miguel de Horcasitas (marzo 8 de 2008). 


\section{Conclusiones}

La escasez enfrentada por los campesinos, de 1938 a 1955, guarda relación con la forma de distribución del agua en este territorio semiárido durante un tiempo prolongado de sequía y con los usuarios aguas abajo - propietarios privados y otros ejidatarios.

La construcción original del territorio en que se instala este ejido se entrecruza con su constitución misma y la determina, está relacionada con sus etapas constituyentes, con factores como quiénes eran los solicitantes de la tierra, quiénes los beneficiarios y los perjudicados con el reparto, cuáles las condiciones de los recursos productivos agua y tierra, y también con el modo en que se construye la escasez del recurso agua justo en el periodo inmediato a la conformación del ejido.

La forma en que se enfrentó y resolvió la escasez dependió no sólo de las condiciones materiales, sino de los modos en que se había construido social e históricamente el territorio, y de las formas sociales de las confrontaciones por el control del agua. A través de éstas, unos lo obtuvieron y otros fueron expropiados. Ha sido el enfoque anclado en una tradición teórica clásica el que ha permitido pensar el ámbito ejidal como una territorialidad que no existe sin las pugnas que la generan. No se han encontrado otras conceptualizaciones relacionadas con el control y la lucha por el agua, que instalen con claridad las confrontaciones como observables.

Desde la perspectiva teórico-metodológica que se ha retomado y trabajado, la escasez hace referencia a procesos sociales, se le concibe como una construcción social, como una situación en que el agua es insuficiente para la realización de actividades sociales, resultante del encajamiento o correspondencia entre diversas acciones.

La sequía y escasez no remiten a un mismo tipo de proceso, pero pueden confluir; un periodo prolongado de sequía puede intervenir en el desarrollo de una situación de escasez, porque implica la disminución de agua disponible en un territorio; no obstante, la escasez no resulta de condiciones climatológicas, sino de los modos en que se usa y distribuye el agua en un contexto determinado.

El ejercicio de poder es constituyente de las confrontaciones, la resultante o resolución de un antagonismo dependerá de la cantidad 
de fuerza (poder) material o poder (capacidad de dominación) que expresen las entidades que se enfrentan, del grado de correspondencia entre las acciones de los sujetos, incluso, de las territorialidades involucradas. La sociedad se reproduce a sí misma mediante relaciones de poder, de confrontaciones, debido a las cuales se construyen y destruyen relaciones sociales, o sea, territorialidades.

Una vez que cierta identidad social obtiene el control sobre el agua, define reglas e instala normas jurídicas sobre su distribución y uso; es decir, una normatividad que le permite expropiarla. Sujetos determinados históricamente pueden instalar, desde el ámbito jurídico, reglas de juego sobre la distribución y uso del agua en un contexto; al hacerlo reproducen el dominio preexistente de unos usuarios sobre otros y la relación de poder.

Cuando se habla de la relación entre los hombres y la tierra o los hombres y el agua, se habla en realidad de relaciones entre los hombres en su relación con la tierra o el agua. ¿Quiénes poseen el control de los recursos? ¿cómo actúan al momento de mermar la disponibilidad de agua en un territorio? ¿Cómo actúan cuando el agua resulta insuficiente para la producción? La relación a explicar es entonces la relación entre resolución de la escasez y poder, esto es, de qué manera el poder o las relaciones de poder intervienen en los modos como se enfrenta y resuelve la escasez de agua en localidades que la enfrentan.

\section{Archivos}

Archivo del Registro Agrario Regional Archivo del Registro Agrario Nacional Archivo Histórico del Agua Archivo General del Estado de Sonora Archivo de Concentración de la Gerencia Regional del Noroeste de la CONAGUA 


\section{Bibliografía}

Aboites, Luis. 1998. El agua de la nación. Una historia política de México (1888-1946). México: Centro de Investigaciones y Estudios Superiores en Antropología Social (CIESAS).

y Valeria Estrada (compiladores). 2004. Del agua municipal al agua nacional. Materiales para una historia de los municipios en México, 19011945. México: Comisión Nacional del Agua (CNA)-AHA-CIESAS-El Colegio de México (COlmex).

Almada Bay, Ignacio y José Marcos Medina Bustos. 2001. Historia panorámica del Congreso del Estado de Sonora, 1825-2000. México: Cal y Arena.

Arendt, Hanna. 1974. La condición humana. Barcelona: Seix Barral.

Bakker, J. Karen. 2000. Privatizing Water, Producing Scarcity: The Yorkshire Drougth of 1995. Economic Geography 76 (1): 4-27.

Bojórquez Jusaino, María del Carmen. 2006. El agua en Hermosillo, 1744-1850. Una historia de usos sociales y conflictos. Tesis de maestría, El Colegio de Sonora (COLSON).

Castañeda González, Rocío. 1995. Irrigación y reforma agraria: las comunidades de riego en el valle de Santa Rosalía, Chihuahua, 1920-1945. México: CNA-CIESAS.

2005. Las aguas de Atilxco. Estado, haciendas, fábricas y pueblos, 1880 1920. México: CNA-AHA-CIESAS-COLMEX.

Escobar, Antonio. 2005. Cuatro momentos de un conflicto por el agua en San Luis Potosí: el caso de Rioverde, siglos XvIII-XX. En El agua en la historia de México, editado por ídem., Juan Manuel Durán y Martín Sánchez, 157-183. México: Universidad de Guadalajara y El Colegio de Michoacán (Colmich). 
Fitting, Elizabeth. 2007. 'Más sangre que agua'. Reclamos al Estado en el valle de Tehuacán. En Paisajes mexicanos de la reforma agraria. Homenaje a William Roseberry, editado por Juan Manuel Durán, Martín Sánchez y Antonio Escobar, 37-70. Zamora: COLMich.

Foucault, Michel. 2001. El sujeto y el poder. En Michel Foucault: más allá del estructuralismo y la hermenéutica, editado por Hubert L. Dreyfus y Paul Rabinow. México: Universidad Nacional Autónoma de México (UnAm).

1979. Microfísica del poder. Madrid: La Piqueta.

Grosby, Steven. 1997. Borders, Territory and Nationality in the Ancient Near East and Armenia. Journal of the Economic and Social History of the Orient 40 (1): 1-29.

Kloster, Karina. 2008. La determinación de lucha por el agua en México: un análisis de los procesos nacionales y locales. Tesis doctoral. Facultad de Ciencias Políticas y Sociales, UNAM.

Lacoste, Ives. 1977. La geografía: un arma para la guerra. Barcelona: Anagrama.

Lieven, Dominic. 1999. Dilemmas of Empire 1850-1918. Power, Territory, Identity. Journal of Contemporary History 34 (2): 163-200.

Lyman M. Stanford y Scott B. Marvin. 1967. Territoriality: A Neglected Sociological Dimension. Social Problems 15 (2): 236-249.

Maass, Arthur y Raymond Anderson. 1976. ... and the Desert shall Rejoice. Conflict, Growth and Justice in Arid Environments. Cambridge: The Massachusetts Institute of Technology Press.

Marín, Juan Carlos. 1995. Conversaciones sobre el poder. Una experiencia colectiva. Buenos Aires: Universidad de Buenos Aires.

Moreno, José Luis. 2006. Por abajo del agua. Sobreexplotación y agotamiento del acuífero de la Costa de Hermosillo, 1945-2005. Hermosillo: Corson. 
Murray, R. Wickett. 2000. Contested Territory: Whites, Native Americans, and African Americans in Oklahoma, 1865-1907. Baton Rouge: Louisiana State University Press.

Padilla Calderón, Esther. 2008. Construcción social de un territorio: agua, poder y escasez en el ejido San Miguel de Horcasitas y su anexo Los Ángeles, 1938-1955. Tesis de doctorado, Colson.

Palerm, Jacinta y Tomás Martínez. 2000. Antología sobre pequeño riego. Organizaciones autogestivas, volumen III. México: Plaza y Valdez Editores y Colegio de Posgraduados.

Piaget, Jean y Rolando García. 1984. Psicogénesis e historia de la ciencia. México: Siglo xxi.

Sánchez, Martín. 2005. "El mejor de los títulos”. Riego, organización social y administración de recursos hidráulicos en el Bajío mexicano. Zamora: COLMich.

Sheridan, Thomas. 1988. Where the Dove Calls:The Political Ecology of a Peasant Corporate Community in Northwestern Mexico. Tucson:The University of Arizona Press.

Weber, Max. 2004. Economía y sociedad. Esbozo de sociología comprensiva. México: Fondo de Cultura Económica.

Wittfogel, Karl. 1966. Despotismo oriental: estudio comparativo del poder totalitario. Madrid: Guadarrama.

Wolch, Jennifer y Michael Dear. 1988. The Power of Geography: How Territory Shapes Social Life. Boston: Unwyn Hyman.

Worster, Donald. 1985. Rivers of Empire. Water, Aridity and Growth of the AmericanWest.Oxford: Oxford University Press. 